\title{
Using Asynchronous Discussions to Enhance Student Participation in CS Courses
}

\author{
Bhagyavati \\ Columbus State University \\ 4225 University Avenue \\ Columbus, GA 31907 \\ 1-706-565-3519 \\ bhagyavati@colstate.edu
}

\author{
Stan Kurkovsky \\ Columbus State University \\ 4225 University Avenue \\ Columbus, GA 31907 \\ 1-706-565-3520 \\ kurkovsky_stan@colstate.edu
}

\author{
Christopher C. Whitehead \\ Columbus State University \\ 4225 University Avenue \\ Columbus, GA 31907 \\ 1-706-565-3527 \\ whitehead_christopher@colstate.edu
}

\begin{abstract}
As Computer Science (CS) educators, we are involved in teaching a variety of undergraduate and graduate courses such as database management systems, networking, software development and web development courses. In addition to the traditional classroom environment, we use online and blended teaching methods to enhance student participation and improve the achievement of learning objectives. Typical online supplements to classroom instruction include posting homework, links to external resources, lecture notes and exams online. Asynchronous discussions and synchronous chat sessions provide additional forums outside the classroom for strengthening interaction and enriching the learning experience for students. This paper focuses on how asynchronous discussions can be used to enhance student participation in CS courses; increased participation leads to learning effectiveness, rich involvement with the course content, and student satisfaction.
\end{abstract}

\section{Categories and Subject Descriptors}

K.3.1 [Computer Uses in Education]: Computer-assisted instruction (CAI), Computer-managed instruction (CMI), Distance learning.

\section{General Terms}

Management, Experimentation, Human Factors, Measurement.

\section{Keywords}

Curriculum, Computer Science, Asynchronous Discussions, Student Participation, Course Related, Split Deadlines, Classroom Management, Learning Communities, Student Engagement.

\section{INTRODUCTION}

The number of higher education institutions that offer at least one fully online or blended course has grown significantly in recent years [1]. Computer Science educators are experimenting with online modules and courses, just as their counterparts in other Permission to make digital or hard copies of all or part of this work for personal or classroom use is granted without fee provided that copies are not made or distributed for profit or commercial advantage and that copies bear this notice and the full citation on the first page. To copy otherwise, or republish, to post on servers or to redistribute to lists, requires prior specific permission and/or a fee.

SIGCSE'05, February 23-27, 2005, St. Louis, Missouri, USA.

Copyright 2005 ACM 1-58113-997-7/05/0002...\$5.00. disciplines. While academic leadership believes that the quality of online education matches that of the traditional, face-to-face instruction, faculty has been more conservative in their enthusiasm [1], [10]. The majority of CS educators supplement classroom instruction with web-based enhancements such as posting a syllabus on a website, maintaining a repository of external links and resources and so on.

In the context of modern CS education, the question of online instruction being "as good as" face-to-face instruction has been substituted by the question of how an online environment can provide benefits unavailable in traditional classroom environments. An online component that assists in providing additional benefits to students is the asynchronous discussion implemented as threaded discussion topics. If the full potential of this tool is realized by CS educators, student participation in their courses will be enhanced, thereby maximizing learner effectiveness, student satisfaction and achievement of learning objectives. By offering a richer environment for interaction than the traditional classroom, asynchronous discussions help address several problems inherent in the traditional approach to studentstudent and student-instructor interaction, which manifest themselves very prominently in most CS courses.

Asynchronous discussion assignments typically comprise a significant component of online and blended environments, and may provide meaningful complements to classroom instruction and student interaction. In this paper, we address the specific issues of topic selection and scheduling of asynchronous discussions so that student participation is maximized for an optimal learning experience within the CS curriculum. Asynchronous discussion topics, if chosen carefully, facilitate the formation of communities that can lead to success in the course [12]. We present our experiences in using asynchronous discussion topics that have proven to be effective in enhancing student participation in our courses. We also describe the issues involved in scheduling discussions that affect successful achievement of learning outcomes. These learning outcomes are specifically focused on CS students and courses which require direct application of the course material.

\section{BACKGROUND}

The potential of asynchronous discussions to enhance student participation and effective learning has long been recognized [2]. We believe that asynchronous discussions are necessary components of CS courses because of the richness of student 
interaction obtainable by them [13], [15]. Online asynchronous discussions also address several problems inherent in classroom discussions: presence of silent and passive students; lack of time; lack of prepared and thoughtful responses; propensity to venture off-topic; lack of focus; and lack of student involvement [11]. Graded asynchronous discussions trivialize the concerns of passivity in students, lack of involvement, lack of focus and preparation. In addition, if responses to these discussions are part of the overall grade of the course, moving them online overcomes the pressure of time typically present in a classroom discussion.

Carefully chosen topics enhance student involvement and keep students engaged in the learning process. Discussions that challenge traditional thinking motivate students to seek external sources to defend their opinions in discussion responses [4]. Peer support and encouragement have a tendency to form strong learning communities, which are instrumental in enhancing student participation and interaction between peers and with the instructor [3]. A learning community of peers motivates students to seek more sources of information than the recommended sources by the instructor; peers continually challenge and support each other in a community. Timely and open-ended questions are more effective in provoking stimulating debate than questions to which answers can be easily found in the textbook [9].

For example, a discussion on the Patriot Act in Computer Security and Information Assurance courses provides more responses than those motivated by grade and course credit. In a recent discussion on opinions about the sharing of airline passenger data with the government, pro-privacy and pro-security students were quite passionate about voicing their divergent opinions. When questioned by peers or by the instructor, students successfully found independent sources to corroborate their viewpoints. Thus, asynchronous discussion topics can be selected to maximize participation and optimize learning outside the classroom. The authors have been successful in incorporating such interesting and even provocative topics into the context of many CS areas such as database management, web development, software development and network security courses, thus enlarging upon the classroom experiences of the students.

Many topics requiring student involvement in independent research fit perfectly into the framework of asynchronous discussions as well. As an example, consider the research involved in obtaining relevant sources of information on security features of the .NET Framework. Ordinarily, this research requires many hours of work for an individual. However, if assigned as a project to a team of students, such a task may lead to a deeper and more informed discussion among team members. In the process of sharing thoughts and debating over important issues within their team, students often come up with thorough and detailed answers to discussion questions. Such interaction is most effective in online asynchronous mode because each participant needs preparation time to provide insightful and relevant summaries independent of other team members. At the same time, contributions of individual members are clearly visible to the instructor and peers, who can critique and assist in development of a deeper understanding of the material than possible in a faceto-face environment.

During the process of researching material, summarizing it independently of team members and posting responses to discussion topics, students often synthesize a collective point of view to the ongoing discussion. For example, a team leader may distill the individual responses of the team members into a cohesive team summary. Therefore, asynchronous discussions add another important feature to the learning process - cultivating the culture of teamwork among students. In today's office environment, teamwork is prevalent in almost all areas of computer science; this added feature of the asynchronous discussion can have a significant impact on students' success in the workplace.

However, without active instructor involvement, students can lose interest and become repetitive in their responses, thereby defeating the purpose of asynchronous discussions. Instructors have to be vigilant in choosing current, relevant and open-ended topics [6]; if the topic lends itself to an easy answer, students quickly become disillusioned after the first few responses because they will not perceive the purpose in rephrasing the same responses. Instructor involvement is also necessary to keep the discussion focused, on track and professional. It is typical to become heavily involved in the beginning, posting a response to almost every student; such in-depth involvement is not required after students become comfortable with the format and expectations of the discussions. Later topics generate more discussion than initial topics, which, along with the formation of learning communities necessitates reduced instructor involvement as the course progresses through the term [5].

\section{SIGNIFICANT ISSUES}

Several issues impact the effect of asynchronous discussions on student participation and interaction in CS courses. The number of students, nature of the course, primary delivery mode of course content, duration of the course, level of preparedness of the students, the number of topics in a discussion, relevance and type of topics, time assigned for completion of the discussion, percentage of grade allocation and scheduling of due dates are some of the issues we managed effectively through our combined teaching experience. We present two important issues in greater detail below. The nature and type of topics, and scheduling of discussion due dates are significant issues affecting student participation. While effective practices in topic selection can be measured by qualitative means, best practices in scheduling have been supported by quantitative means.

\subsection{Topic Selection}

As CS instructors, we each differ in our approach to asynchronous discussion in our courses. While there are some similarities, such as weekly discussions and grade-mandated responses, the selection and number of topics we present to our students varies. The number of topics changes according to the primary delivery mode of course content: in a course taught exclusively online, the discussion comprises a major component of the course grade, ranging from 35 to $50 \%$ of the overall grade; in a course taught mostly through traditional lectures, the discussion moves online from the classroom due to lack of time; in a blended course taught in the traditional classroom and supplemented heavily via online means, asynchronous discussion occupies the middle ground between the other two modes.

The number of asynchronous discussions in a course also varies based on the duration of the term - summer courses typically generate less number of topics than fall or spring term courses. Nevertheless, irrespective of the primary delivery mode of the 
class, each of the authors typically engages in weekly discussions online; in other words, a new discussion is opened for students every week. In a weekly discussion, the number of topics is likely to vary between 1 and 4, depending on the number of students, nature of the subject matter, duration of the course, and the interest of the instructor and students.

One of the authors initially started with presenting one topic per weekly discussion. If the number of students in the course ranged between 20 and 30, student-to-student interaction was sufficiently motivated to gain and maintain the momentum required for effective participation in the learning experience. However, if the number of students in the course was less than 15, the presence of a lone topic did not pose an adequate challenge to students, and responses became stilted and repetitive. This problem was remedied by presenting a choice of 2 topics per weekly discussion to sustain the interest level of students in the smaller classes. The topics were related and each student had the choice of responding to one or the other topic. Each student also had to comment on a peer's response to the topic they had not originally chosen. This format enabled variety in responses, thus stimulating greater debate and interaction among students.

Another author requires students to respond to two or three discussion questions concerning the course content, and to respond to a question that requires students to summarize either Internet sources or peer-reviewed/refereed journal articles relevant to the course topic every week. This allows students to independently research computer science areas of interest to them and to acquire knowledge not presented in the course textbook. For software or web development courses, students are also required to post their completed assignments, to describe those assignments, and to describe their "trials and tribulations" in completing them. This technique allows students to see and comment on each other's developmental techniques and to share their experiences with other students. In courses requiring projects, students are also required to post their project deliverables and to comment on other students' deliverables. This technique of varying the required types of responses aids in addressing the different learning styles of the students [7]. Requiring students to comment substantively on classmates' responses encourages them to consistently review other student responses, independently compare these posts to their own and think critically about their own and others' responses.

In the CS curriculum, several courses are enriched by careful selection of topics in asynchronous discussions. Courses involving software development, network and information security, web design and development, and database management systems compel independent, external research among students, which are borne out in discussion responses to thought-provoking topics. Project-based and current topics courses also require experiences involving students beyond the classroom. Because CS students can be motivated by timely hot-button issues such as the privacy and security of biometric identification schemes, the selection of relevant topics for engaging students in asynchronous discussions becomes especially important for CS educators.

\subsection{Scheduling Due Dates}

We have been engaged in using asynchronous discussions in each of the 3 courses we teach every term, including the summer term. For the last 3 years, each of us has followed different models for topic selection and scheduling due dates for discussions. We typically compare notes on teaching methods, "sit" in on virtual and classroom sessions, exchange ideas on effective practices, and actively participate in professional meetings in the field. Although each author uses the week as a standard format for a discussion, due dates for student responses have been differently scheduled. While one of the authors mandates at least 2 posts per week for grade purposes, another author expects as many as 5 posts per week per student. In addition, in some courses, students are required to post at least one comment to another student's response. This may result in a minimum of 10 posts per week.

Initially, the authors struggled with a single due date for student responses in a week. In some courses, responses were due on Sunday; in others, on Saturday; and in others, on Friday. Since a majority of the students posted their original responses a day before the deadline or on the day of the deadline, regardless of the day of the week of that deadline, there was little time for reading and commenting upon peer responses. Initial discussion topics were laced with one-line comments such as "Great response" or "Good job!" The overhead on instructor time spent on grading also occurred in bursts with periods of little or no grading activity interspersed with periods of intense grading activity.

After a week or two of unsatisfactory responses and marathon grading sessions, one of the authors decided to split the discussion deadline in half - students now needed to post an original response to one of two weekly topics by mid-week; they had until the end of the week to read, understand and comment on peer responses to the other topic. This model immediately improved student participation: students' comments were meaningful, and they sought clarification or added to the substance of the original response. Some students expressed disagreement with their peers' responses, which stimulated lively defenses from the original respondents. Distributed deadlines for weekly topics are now the norm in asynchronous discussions of all the courses that all of the authors teach every term.

From our experiences and survey of literature, we present two additional techniques for improving student interaction:

- clearly state the requirements of discussion responses, such as length required, due date, stylistic requirements (if any) and percentage of grade, up front either in the syllabus or in a "welcome" message to students [14]; and

- provide timely feedback to the students, particularly in the beginning of the term before learning communities have been formed [8].

By clearly stating the requirements for effective interaction up front and quickly pointing out to students when they are failing to meet expectations, comments such as "Great response!" or "Good job!" have been nearly eliminated. This has resulted in significantly more interactivity throughout the discussions.

Initial ad-hoc experimentation with one discussion topic per week did not provide enough of a challenge to students in CS courses. From personal experience in taking online courses, the authors know that one topic to discuss per week is too light a load to maintain interactive momentum among students. Sporadic posts also undermine the teamwork aspect of the courses. Providing two or more topics per weekly discussion presented an adequately challenging assignment to most CS students. Plurality of topics 
also sustained daily and meaningful interaction among students and between students and instructor. The final adjustment in asynchronous discussions to exploit their full potential occurred as a result of splitting the response and comment deadlines among students. Such a distribution of deadlines, coupled with multiple, related, relevant and timely topics per weekly discussion, furnished optimal interactivity and produced optimum engagement of CS students with the course material otherwise presented in traditional lectures and online supplements.

\section{METHODOLOGY AND RESULTS}

We believe that scheduling weekly asynchronous discussions with distributed due dates is more effective in enhancing student participation than scheduling weekly discussions with a single due date at the end of the week. Increasing student participation in discussions has a direct impact on achieving better academic results and learning outcomes by students. This is particularly true in CS courses wherein students are expected to understand the underlying theoretical concepts sufficiently thoroughly in order to apply them in different practical contexts. To substantiate our belief, we quantitatively compare student participation in discussions with single due dates, with participation in discussions with split deadlines. Our basic premise is that split deadlines work better than unified deadlines in eliciting higher student involvement and enriching the learning experience of students in CS courses.

Out of a total of 7-8 undergraduate and graduate courses taught by each of the authors over an academic year, we selected 3 to 4 courses per instructor that best represented teaching style and requirements for online asynchronous discussions. The period of teaching ranged from summer 2003 to summer 2004. Messages in discussion topics were grouped by week and compiled together to get a composite listing of all messages in that discussion. Knowledge of the number of students enrolled in the course enabled us to obtain the number of messages per student. This number was normalized to obtain the number of posted messages per day per student per discussion (Table 1). We refer to this measure as the student participation metric. The final results were compared graphically as shown in Figure 1 a) through d).

Table 1. Sample numeric data for student participation metric

\begin{tabular}{|l|r|r|r|r|}
\hline Day & Course 1 & Course 2 & Course 3 & Course 4 \\
\hline Sun & 0.89 & 1.30 & 0.23 & 0.18 \\
\hline Mon & 0.24 & 0.29 & 0.34 & 0.33 \\
\hline Tue & 0.28 & 0.20 & 0.36 & 0.33 \\
\hline Wed & 0.32 & 0.24 & 0.32 & 0.37 \\
\hline Thu & 0.42 & 0.20 & 0.43 & 0.53 \\
\hline Fri & 0.32 & 0.28 & 1.00 & 1.01 \\
\hline Sat & 0.47 & 0.39 & 0.22 & 0.20 \\
\hline \# students & 17 & 17 & 25 & 15 \\
\hline \# discussions & 7 & 13 & 13 & 13 \\
\hline Deadlines & Sun & Sun & Fri & Fri \\
\hline
\end{tabular}

Figure 1 a) and b) show the student participation metric for courses with unified, non-distributed discussion deadlines. Figure 1 a) shows the data for two courses in which discussion messages were due on Sundays while Figure $1 \mathrm{~b}$ ) shows the data for two courses in which discussion messages were due on Fridays. It is obvious from these two figures that student activity remained relatively low throughout the week, but peaked dramatically on the deadline. Such an approach may encourage students to procrastinate until the last moment. Non-distributed deadlines may lead to the accumulation of work that students need to complete in a short period of time. Our experience indicates that courses with a significant software development component are those that suffer the most when offered in this mode: student performance in coding assignments and software development projects tends to decline. On the other hand, distributed deadlines help keep the students engaged in the course, as explained below.

a)

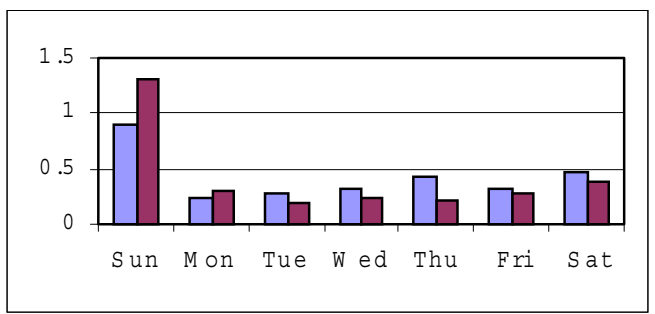

b)

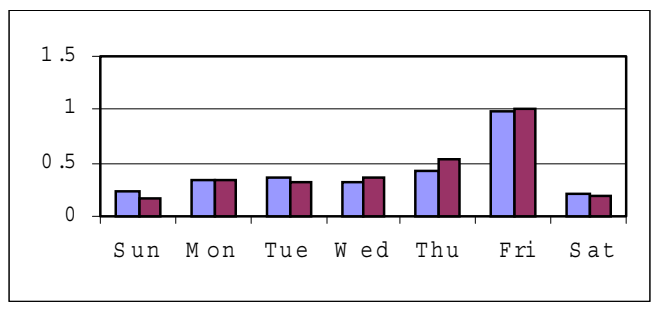

c)

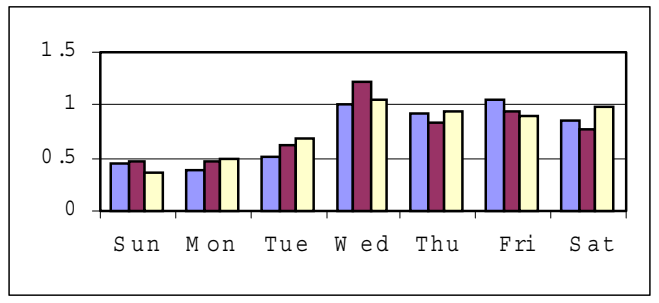

d)

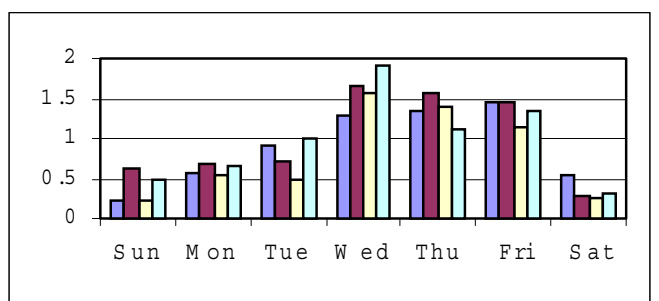

Figure 1. Student participation metric: a) two classes offered by Instructor 1 with a single Sunday deadline; b) two classes offered by Instructor 1 with a single Friday deadline; c) three classes offered by Instructor 2 with a split Wednesday/Saturday deadline; and d) four classes offered by Instructor 3 with a split Wednesday/Friday deadline

Figure $1 \mathrm{c}$ ) and d) show the student participation metric for several courses offered by Instructor 2 and Instructor 3 respectively. As can be clearly seen in these figures, student participation is more uniformly spread throughout the entire workweek. This type of deadline structuring encourages students to plan ahead, which yields significantly positive results in CS courses requiring many hands-on activities, such as software development assignments and projects. In network security and forensics courses, lively debate was engendered by distributing 
the deadlines. There was a marked improvement in student engagement with the subject matter when they were given time to read other students' discussion messages and respond to them appropriately and adequately. Research-oriented courses that require a lot of reading benefit from this structure as well, since students generally have more time to analyze their reading materials and discuss them with other students and the instructor.

As observed by the illustrations, the experimental results clearly demonstrate the higher degree of student participation in asynchronous discussions with distributed deadlines for the mandated posts. Our hypothesis that scheduling weekly asynchronous discussions with distributed due dates is more effective in enhancing student participation than scheduling weekly discussions with a single due date at the end of the week has been borne out by the data. Student survey responses, to be presented at the conference, strongly support this result. An increase in student participation in discussions related to the course has a direct impact on increasing student engagement and involvement with the material. This is especially true in CS courses because of the practical content delivered and the need for students to grasp applications of the concepts studied in lectures.

\section{CONCLUSION}

This paper focused on effective teaching practices that can be used to enhance student participation and involvement in CS courses. Asynchronous discussion can lead to successful learning outcomes and enhanced student satisfaction. In our collective experience, student participation and achievement of learning outcomes can best be increased by following good practices. These practices relate to online asynchronous discussions in tandem with online or traditional instruction in CS courses:

- posting discussion topics that are timely and relevant to the course material,

- providing a multiplicity of carefully chosen weekly topics, and

- distributing response deadlines on topics such that sufficient time is granted for understanding others' messages so students can post constructive criticism and supplemental information.

Lively and involved discussions conducted asynchronously in an online forum also accelerated the generation of learning communities, thus enhancing the learning experience. Qualitative data, anecdotal evidence and a survey of research literature supported our theories of topic selection and the need for multiple topics per weekly discussion. Quantitative data were collected to evaluate the theory of distribution of response deadlines. The results of the evaluation confirmed our belief that split deadlines worked better than unified deadlines in fostering higher and frequent interaction among students. The beneficial implications of our work can be realized by all CS educators in improving student participation and satisfaction, and stimulating students to seek current knowledge via external and independent research into topics pertaining to course content and learning objectives.

\section{REFERENCES}

[1] Allen, I. E., Seaman, J. Sizing the Opportunity: The Quality and Extent of Online Education in the United States, 2002 and 2003. The Sloan Consortium, September 2003. http://www.sloan-c.org/resources/sizing_opportunity.pdf
[2] Anderson, T., and Elloumi, F., editors. Theory and Practice of Online Learning. Ngwenya, J., Annand, D., and Wang, E., authors: Chapter 13 - Supporting Asynchronous Discussions among Online Learners. Athabasca University, 2004. http://cde.athabascau.ca/online_book/pdf/TPOL_book.pdf

[3] Bhagyavati and Whitehead, C. Facilitating Learning Communities. In Proceedings of the Society for Information Technology and Teacher Education (Atlanta, GA, March 16, 2004).

[4] Cereijo, M. V. P., Young, J., and Wilhelm, R. W. Factors Facilitating Student Participation in Asynchronous WebBased Courses. Journal of Computing in Teacher Education, 18, 1 (Fall 2001), 32-39. http://www.iste.org/jcte/pdfs/te18132cer.pdf

[5] Dudding, C., Gauthier, A., Naderi, N., and Scot, T. Learning Communities, Asynchronous Discussions: Asynchronous Discussion Guide. University of Virginia, May 11, 2002. http://onlinelearn.edschool.virginia.edu/discuss/design/async h_disc_guide_blank.pdf

[6] Frey, B. A., and Wojnar, L. C. Successful Synchronous and Asynchronous Discussions: Plan, Implement and Evaluate. Educause Information Resources Library, 2004. http://www.educause.edu/ir/library/pdf/MAC0426.pdf

[7] Hardless, C., Lundin, J., and Nulden, U. Mandatory Participation in Asynchronous Learning Networks. In Proceedings of the 34th Hawaii International Conference on System Sciences (2001). http://www.alnresearch.org/ Data_Files/articles/full_text/hardless.pdf

[8] Kelly, J. On-line Discussions: Making them work for you. JISC InfoNet Key Issues. Northumbria University, 2003. http://www.jiscinfonet.ac.uk/InfoKits/infokit-related-files/online-discussions

[9] Kurkovsky, S., Bhagyavati, Summers, W., and Whitehead, C. Online Discussions in Computer Science Courses: How to Make Them an Effective Learning Tool. In Proceedings of the Information Technology in Research and Education (London, United Kingdom, June-July 2004).

[10] McDonald, J. Is "As Good as Face-to-Face" As Good As It Gets? Journal of Asynchronous Learning Networks, 6, 2 (August 2002).

[11] Murray, B. Reinventing Class Discussion Online. Monitor on Psychology, 31 (April 2000). 54-56.

[12] Pelz, B. (My) Three Principles of Effective Online Pedagogy. Journal of Asynchronous Learning Networks, 8, 3 (June 2004). Sloan Consortium. http://aln.org/publications/jaln/v8n3/v8n3_pelz.asp

[13] Raleigh, D. Keys to Facilitating Successful Online Discussions. Teaching with Technology Today, 7, 3 (November 15, 2000). http://www.uwsa.edu/ttt/raleigh.htm

[14] SUNY. Enhancing Online Discussion. Teaching, Learning and Technology at State University of New York, June 28, 2004. http://tlt.suny.edu/discussion.htm

[15] Wu, D., and Hiltz, S. Online Discussions and Perceived Learning. In Proceedings of the 9th Americas Conference on Information Systems (Tampa, FL, August 2003). pp. 687-696 